\title{
Is Environmental Radon Gas Associated with the Incidence of Neurodegenerative Conditions? A Retrospective Study of Multiple Sclerosis in Radon Affected Areas in England and Wales
}

\author{
Groves-Kirkby, C. J., Denman, A. R., Campbell, J., Crockett, R. G. M., Phillips, P. S. \& \\ Rogers, S.
}

\begin{abstract}
To test whether an association exists between radon gas concentration in the home and increased multiple sclerosis (MS) incidence, a retrospective study was undertaken of MS incidence in known areas of raised domestic radon concentration in England and Wales, using The Health Improvement Network (THIN) clinical research database.
\end{abstract}

The study population comprised 20,140,498 person-years of clinical monitoring (males: 10,056,628: 49.93\%; females: 10,083,870: 50.07\%), representing a mean annual population of 2.5 million individuals. To allow for the possible latency of MS initiation following exposure, data extraction was limited to patients with at least five years registration history with the same GP practice before first diagnosis. Patient records were allocated to one of nine radon concentration bands depending on the average radon level in their postcode sector.

MS incidence was analysed by searching for patients with first MS diagnosis over the eight calendar years 2005 to 2012 inclusive. 1,512 new MS cases were diagnosed, 1,070 females, 442 males, equivalent to raw incidence rates of $7.51,10.61$ and 4.40 per $10^{5}$ person-years respectively, comparable to previously reported results. Of these new cases, 115 could be allocated to one of the radon bands representing high radon areas.

Standardising to the UK 2010 population, excess relative risk (ERR) figures for MS were calculated for each radon band. Linear regression of ERR against mean band radon concentration shows a positive gradient of 0.22 per $100 \mathrm{~Bq} \cdot \mathrm{m}^{-3}\left(R^{2}=0.25, p=0.0961\right)$ when forced through the origin to represent a linear-no-threshold response. The null hypothesis falls inside the $95 \%$ confidence interval for the linear fit and therefore this fit is not statistically significant. We conclude that, despite THIN sampling around 5\% of the population, insufficient data was available to confirm or refute the hypothesised association between MS incidence and radon concentration.

\section{Keywords}

Radon

Multiple Sclerosis

Retrospective population-based study

Clinical extraction database 


\section{Is Environmental Radon Gas Associated with the Incidence of Neurodegenerative Conditions? A Retrospective Study of Multiple Sclerosis in Radon Affected Areas in England and Wales}

\section{Introduction}

\subsection{Environmental Radon Gas}

\subsubsection{Origins}

Radon, a naturally occurring radioactive gaseous decay product of uranium, is widely distributed in the environment in rocks and soils, with varying geographical concentration, and in building materials incorporating or manufactured from these. On generation, radon migrates to the atmosphere by diffusion and convection, giving a mean outdoor air concentration in the British Isles in the range $4-6 \mathrm{~Bq} \cdot \mathrm{m}^{-3}$ (Wrixon et al., 1998; Gunning et al., 2014). Although radon dissipates rapidly in outdoor air, it concentrates in the built environment, typical ingress routes being cracks in walls and floors, and drains and loose-fitting pipes, the mean UK domestic radon concentration being around $20 \mathrm{~Bq} \cdot \mathrm{m}^{-3}$ (Wrixon et al., 1998).

\subsubsection{Physiology and Health}

The most significant radon isotope, ${ }^{222} \mathrm{Rn}$, decays by $\alpha$-emission (half-life 3.8 days) via ${ }^{218} \mathrm{Po}$ and

${ }^{214} \mathrm{Bi}$ (both also $\alpha$-emitters) to ${ }^{210} \mathrm{Po}$, the final decay product being the stable lead isotope ${ }^{206} \mathrm{~Pb}$. These heavy-metal daughters, all highly toxic and readily adsorbed onto atmospheric particles and lung tissue, pose a significant health hazard, inhalation of ${ }^{222} \mathrm{Rn}$ and its progeny providing the majority of the radiation dose received by the respiratory system (Darby et al., 2001). A direct consequence of the trapping of radon decay products in the lung has been the association between enhanced levels of environmental radon and increased risk of lung-cancer, leading to recognition of radon as a significant factor in the incidence of lung-cancer among smokers (BEIR, 1999).

Radon, nearly two orders of magnitude more soluble in polar hydrocarbons than in water, is lipidsoluble, its solubility depending on the number of carbon atoms per lipid molecule and peaking in the region of heptanoic acid at a level 7.4 times that in ambient air (Lykken and Momčilović, 2003, 2006). Radon forms clathrates with water and alcohols, both abundant in animal tissue. Although most inhaled radon is immediately exhaled, some becomes trapped in the lungs and migrates to the blood-stream, where it is soluble at a level of $42 \%$ of its solubility in water at $310 \mathrm{~K}$ (Knaffl-Lenz, 1912; IUPAC, 1979), moving freely around the body, including into and out of the brain despite the blood-brain barrier. In contrast, radon's lipid-insoluble neurotrophic and neurotoxic heavy-metal decay products remain trapped at the locations where they are generated, acting as localised sources of radioactivity and heavy-metal toxicity, causing radiation damage and chemical injury to body cells.

\subsubsection{Geographical Occurrence}

Environmental radon concentration levels are geographically variable in response to local geological conditions, and may fluctuate significantly across relatively small distances. This is particularly true in the British Isles, which possess a complex geology extending continuously from the Pre-Cambrian to the Holocene. In mainland Britain, the highest domestic radon concentration levels are associated with the granite of the south-west peninsula (Devon and Cornwall). Elevated radon levels also occur along the Jurassic escarpment crossing the Midlands from Somerset to Lincolnshire, in the Derbyshire Peak District, and in well-defined localities in the Welsh borders and in Aberdeenshire in Scotland. In Ireland, high radon areas are distributed principally along the South-East and North-West coastal areas, with outliers in Co. Kerry in the Republic of Ireland (RoI) and in Co. Armagh in Northern Ireland. Figure 1 compares (a) the geographical distribution of radon across the UK (NRPB, 2000) and (b) an indication of the complex bedrock geology 
underlying the observed radon variability generated using Make-a-Map (BGS, 2015), an interactive online geological map of the British Isles provided by the British Geological Survey ${ }^{1}$.

Radiation protection in England and the Devolved Administrations (Scotland, Wales and Northern Ireland) within the United Kingdom (UK), formerly administered by the National Radiological Protection Board (NRPB), is currently the responsibility of the Centre for Radiation, Chemical and Environmental Hazards ${ }^{2}$ (CRCE), lately part of the UK Health Protection Agency (HPA) and now a division of Public Health England. The Radiological Protection Institute of Ireland (RPII) fulfils the same function in the RoI. Responding to the health threat posed by domestic radon in the UK, the NRPB initially established a residential Action Level of $200 \mathrm{~Bq} \cdot \mathrm{m}^{-3}$ (NRPB, 1990), declaring as Radon Affected Areas (RAAs) those geographical entities where over 1\% of domestic measurements showed radon concentrations above the Action Level. Initially comprising Devon, Cornwall, parts of Somerset, Northamptonshire and Derbyshire, subsequent study by NRPB and its successors has identified further RAAs in England and Wales, with increasingly enhanced geographical resolution (Miles et al., 1996). Numerical and cartographical data on RAAs are published in the Radon Atlas for England and Wales (Green et al., 2002; Miles et al., 2007, Rees et al., 2010), reporting radon levels at scales ranging from county to postcode sector. Corresponding atlases are published by CRCE for Scotland (Miles et al., 2011) and Northern Ireland (Daraktchieva et al., 2015), and by RPII for the RoI (Fennell et al., 2002; Hodgson et al., 2014).
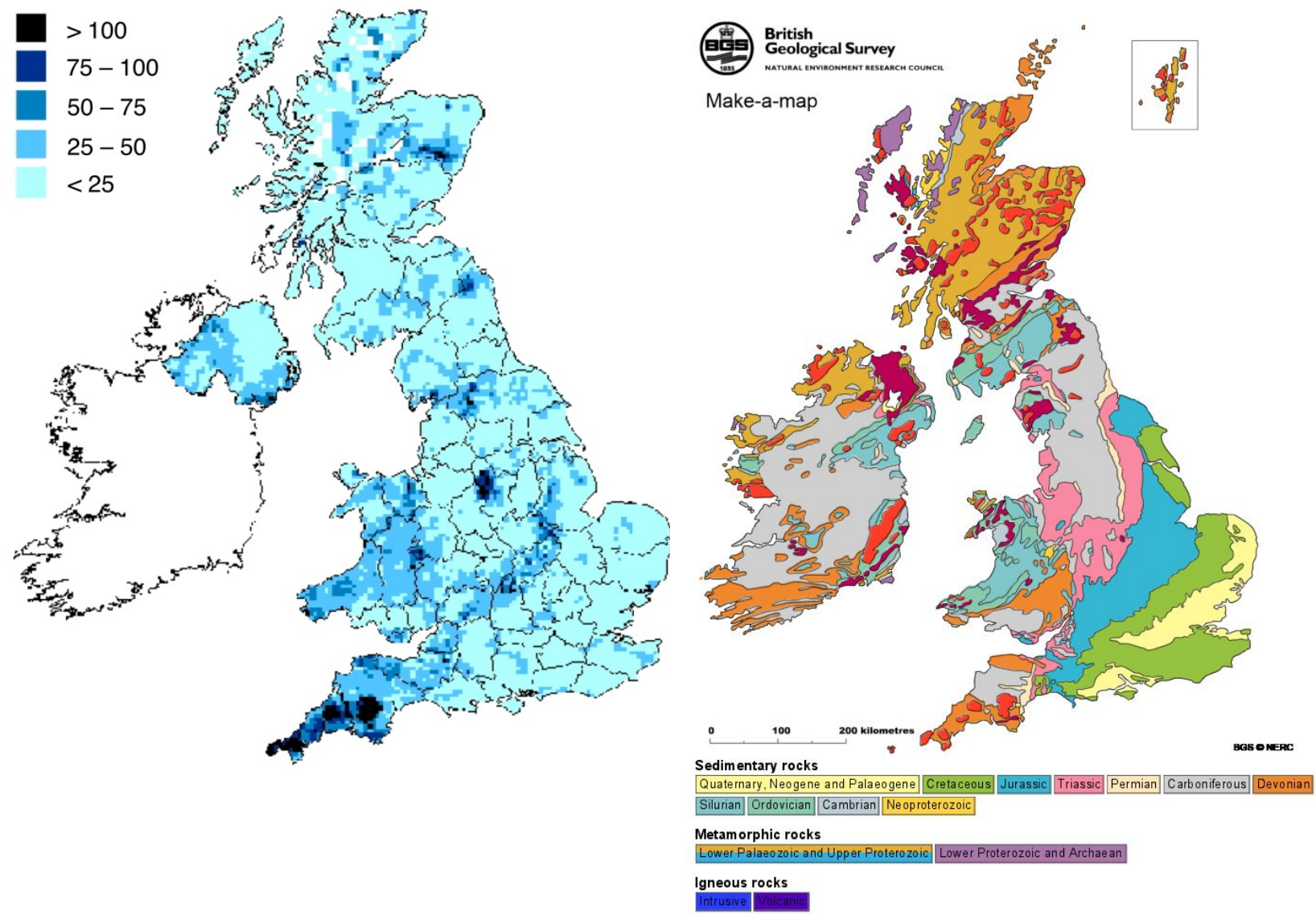

(a)

(b)

Figure 1: (a) Distribution of domestic radon across the United Kingdom (NRPB, 2000). Units $\mathrm{Bq} \cdot \mathrm{m}^{-3}$.

\footnotetext{
${ }^{1}$ British Geological Survey, Keyworth, Nottingham, NG12 5GG, UK.

${ }^{2}$ CRCE, Chilton, Didcot, Oxfordshire, OX11 0BR, UK
} 
(b) Simplified bedrock geology of the British Isles. Source: BGS Make-a-Map. Online at: http://www.bgs.ac.uk/discoveringgeology/geologyofbritain/makeamap/home.html Reproduced with the permission of the British Geological Survey CNERC. All Rights Reserved.

Research has identified substantial geographical variability in domestic radon concentrations, demonstrating spatial correlation between mean annual radon concentration and the underlying geology, and studies of the influence of radon on the incidence of radon-induced conditions, principally cancers and cancer-related diseases, have been reported. Metadata analysis of thirteen European case-control studies (Darby et al., 2005) demonstrated the excess relative risk (ERR) of residential radon-induced lung-cancer to be 0.16 per $100 \mathrm{~Bq} \cdot \mathrm{m}^{-3}(95 \%$ C.I. $0.05-0.31)$. A contemporaneous North American study (Krewski et al., 2005) reported ERR of 0.18 per $100 \mathrm{~Bq} \cdot \mathrm{m}^{-3}(95 \%$ C.I. $0.02-0.43)$, compatible with the previous ERR estimate from the same team of 0.12 (Lubin et al., 1997), predicted by extrapolation from the earlier Colorado Miners studies (Lubin et al., 1995). Independent meta-analysis of seventeen studies worldwide (Pavia et al., 2003), some of which formed the basis of the later, more focussed, studies, reported ERR at $150 \mathrm{~Bq} \cdot \mathrm{m}^{-3}$ of $0.24(95 \%$ C.I. $0.11-0.38)$, equivalent to 0.16 per $100 \mathrm{~Bq} \cdot \mathrm{m}^{-3}$. More recently, a Canadian population-based case-control study (Hystad et al., 2014) found positive association between lungcancer incidence and domestic radon exposures derived from maps, with ERR of 0.13 per $100 \mathrm{~Bq} \cdot \mathrm{m}^{-3}(95 \%$ C.I. $-0.12-0.46)$.

Although epidemiological studies have confirmed a link between domestic radon exposure and increased lung-cancer risk, with further studies suggesting that other cancers, especially leukaemia, kidney cancer, and malignant melanoma, are related to indoor radon, direct radon causality of other cancers has not been convincingly demonstrated. The current view is that if radon and its decay products do have carcinogenic effects on organs other than the lung, then the effect is so weak as to be generally undetectable in the published epidemiological studies (AGIR, 2009).

\subsection{Multiple Sclerosis and Radon}

In addition to lung-cancer and related conditions, environmental radon exposure has been postulated to be responsible for the triggering, often late in life, of certain neurodegenerative conditions, including Alzheimer's and Parkinson's diseases (Momčilović et al., 2001), motor neurone disease (Nielson et al., 1996), and multiple sclerosis (MS) (Bølviken et al., 2003; Eidbo and Prater, 2004; Gilmore and Grennan, 2003; Neuberger et al., 2011). Pilot studies of the influence of geographic variability, and hence, indirectly, of the influence of local radon concentration, on the incidence of non-cancer conditions, particularly MS, have been reported, and are discussed in more detail subsequently.

\subsubsection{Aetiology and Prevalence}

Multiple sclerosis, a disorder of the central nervous system, manifests as acute focal inflammatory demyelination and axonal loss with limited re-myelination, culminating in the chronic multifocal sclerotic plaques from which the disease gets its name (Compston and Coles, 2003). On a global scale, prevalence increases with latitude in both hemispheres (Kurtzke, 2000; Simpson et al., 2011), with broad areas of Africa and Asia relatively unaffected. MS is the most common cause of serious neural disability in young adults in the UK, with exposure to some environmental agent before the age of 15 years being postulated as a factor in its later development in genetically susceptible individuals (Compston et al., 1998). Belbasis et al. (2015), in a recent umbrella review of systematic reviews and meta-analyses of environmental risk factors, noted that the causes of MS are still largely unknown. Early studies of MS in the UK were supportive of an increasing latitudinal gradient between the south of England and the north of Scotland (Swingler and Compston, 1986). Re-analysis of earlier results suggests that evidence for a latitudinal gradient within England is less 
convincing (Robertson and Compston, 1995), although increased prevalence remains in Scotland compared with England and Wales (Forbes and Swingler, 1999).

\subsubsection{Possible Mechanism for Radon}

The oligodendrocyte, a principal target of immune attack in MS, synthesises and maintains the myelin sheath of up to 40 neighbouring nerve axons in the central nervous system. Compact myelin consists of a condensed membrane, spiralled around axons to form the insulating segmented sheath needed for saltatory axonal conduction. In MS, the lipoproteins of the myelin sheaths around the axon of the nerve cell are lost in a degenerative process of demyelination, severely affecting saltatory conduction. Lykken and Momčilović (2003a, 2003b) proposed that myelin sheath lipids take up inhaled lipid-soluble environmental radon; in this delicate and sensitive environment, subsequent $\alpha$ - and $\beta$-particle bombardment irreversibly damages myelin cell nuclei, puncturing the myelin sheaths beyond the point of repair and causing permanent nerve impulse propagation failure. An additional outcome of this irradiation is free-radical generation, leading to potential peroxidative damage to the myelin lipid portion (Cooper, 1997). Together with other studies (Hursh et al., 1965; Nussbaum and Hursh, 1965), this potentially provides a mechanism for delivering a significant radiation dose to the cells involved in MS.

\subsubsection{Ecological Studies}

A number of northern-hemisphere ecological studies suggest a possible correlation between domestic radon levels and MS, with higher incidence identified in regions with higher mean domestic radon concentrations.

In Ireland, MS prevalence in the mountainous north-west, an area with extensive high-uranium granite bedrock geology and high radon-emission, is among the highest in the island. Good countyby-county correlation was observed between mean radon level and the membership level of MSIreland, with lowest prevalence across the Midlands (Gilmore and Grennan, 2003). A questionnaire survey showed that MS sufferers in the north-west were more likely to be living in their childhood home or its locality, and more likely to live in homes with private (well) water supplies, both factors implying potential higher lifetime radon exposure. Extending this study, Carroll (2005) observed MS clustering in high-radon areas, with sparser distribution in low-radon areas, concluding that the potential for MS development is greater with higher childhood radon exposure, especially among males, and that the observed increased incidence since the 1970s coincides with greater exposure to indoor radon, due to improvements in the housing stock.

Using spatially-moving bivariate correlation, Bølviken et al. (2003) studied MS mortality in 73 rural municipality aggregates in Norway, demonstrating positive correlation $(p<0.01)$ between MS and indoor air radon content, and negative correlation $(p<0.01)$ with precipitation and magnesium fallout. Under their hypothesis, air-borne radon levels are influenced by atmospheric fall-out of magnesium and other marine-origin elements through their ion-exchange with the radon precursor, radium, and by annual precipitation through its effect on soil moisture and outwash of radium and related constituents in the soil. Some of the epidemiological characteristics of MS were shown to be not incompatible with observed environmental conditions, with plausible explanations of the role of environmental radon being offered.

A latitudinal MS prevalence gradient exists in the USA, ranging from 57 per $10^{5}$ in the south to 150 per $10^{5}$ in the north (NMSS, 1994). Following identification of elevated radon concentrations in 92 of the 99 counties in Iowa, Eidbo and Prater (1994) confirmed correspondingly high MS prevalence, using National Multiple Sclerosis Society (NMSS) membership data. Similar correlations, also using NMSS data, were subsequently identified in Idaho, Minnesota and Washington (Eidbo and Prater, 2004). In Washington state, the highest prevalence (255 per $\left.10^{5}\right)$ 
was found in Spokane county, which had the highest radon exposure in the state; King county, with the lowest MS prevalence $\left(121\right.$ per $\left.10^{5}\right)$, is the lowest radon exposure region.

In North Dakota, Lykken et al. (2008) analysed ambient air radon and whole body retention of a radon daughter $\left({ }^{214} \mathrm{Bi}\right)$ from the bedrooms of fifteen MS subjects and fifteen controls with no apparent health problems. Preliminary data indicated that bedroom ${ }^{222} \mathrm{Rn}$ exposure and ${ }^{214} \mathrm{Bi}$ retention were higher in the MS subjects than in the controls.

Neuberger et al. (2011), also noting the latitudinal MS-prevalence and residential radon gradients in the USA, reported a pilot case-control study involving 97 MS patients diagnosed for less than 5 years, and 51 non-MS controls. Although they identified a trend in the radon measurements in the homes of a sub-group resident in one home for at least five years prior to diagnosis, suggesting an increased probability of radon exposure, it did not reach statistical significance (Odds Ratio = 1.98; $95 \% \mathrm{CI}=0.98-3.98, p=0.06)$, the small sample size being deemed a limiting factor.

In a study to assess whether other ionising radiation sources are associated with MS, Axelson et al. (2001) demonstrated correlation between MS and both occupational (Odds Ratio $=4.4,95 \%$ CI 1.6 - 11.6) and diagnostic (Odds Ratio $=1.8,95 \%$ CI 1.2 - 2.6) X-ray exposure from two areas of southern Sweden. Cases were noted where X-ray examination of MS patients accelerated demyelination, suggesting firstly, that ionising radiation bombardment triggers demyelination in susceptible individuals (Peterson et al., 1993) and, secondly, that radiation-induced free-radical generation and oxidative damage are of importance in MS pathogenesis (Cooper, 1997).

\section{Method}

\subsection{Hypothesis}

This study tested the hypothesis that association exists between local domestic radon concentration and MS incidence, by comparing MS diagnosis data, obtained anonymously from patient records held by General Practitioners (GPs) in England and Wales, to the known geographical variation of radon, tabulated by postcode sector in the Radon Atlas of England and Wales (Green et al., 2002). A preliminary estimate of the expected patient numbers and the statistical power of the proposed analysis, made prior to commencing the study, indicated that, for the eight years of incidence data, sufficient statistical power was potentially available to justify the exercise.

\subsection{Study Design}

This was a retrospective population-based study using the clinical database maintained by The Health Improvement Network (THIN) ${ }^{3}$, a computerised longitudinal GP database with demographic scope similar to that of the overall UK population (Bourke et al., 2004). The THIN data recording scheme, initially developed from the General Practice Research Database (GPRD) (Walley and Mantagini, 1997) under a non-exclusive license, collects anonymised clinical data from collaborating practices that use the Vision 360 practice management software ${ }^{4}$, following agreed protocols to preserve anonymity, and collates and organises this information for research purposes. Vision is currently used by approximately 20\% of GPs in England, 30\% in Scotland and Northern Ireland and just over $50 \%$ in Wales.

THIN contains the medical records of 12.4 million patients, 3.6 million of whom are currently registered with a practice and who can be followed prospectively; retrospective data are available for the remaining patients who have either died or transferred from THIN practices. This is equivalent to 85.8 million patient-years of data from 587 general practices in the UK, covering

\footnotetext{
${ }^{3}$ IMS Health, 8-14 St. Pancras Way, London NW1 0QG, UK

${ }^{4}$ Vision: In Practice Systems Ltd, 1a Broughton Street, Battersea, London SW8 3QJ, UK
} 
$5.67 \%$ of the UK population (2013 figures, national breakdown unavailable) (IMS Health, 2015). Patient data in THIN, including clinical notes, referrals, downloaded test results, prescriptions and demographics, are catalogued using Read Codes (Bentley et al., 1996), complemented by Multilex codes identifying prescribed medications. All patient data extracted from practice database systems are fully anonymised and validated and are representative of the entire UK population and each National Health Service (NHS) region (Blak et al., 2011).

\subsubsection{Domestic Radon Concentration Database}

Radon concentration data for England and Wales are publicly available in the Radon Atlas for England and Wales (Green et al., 2002; Miles et al., 2007; Rees et al., 2010), which reports radon concentration levels in administrative and geographical units at granularities ranging from postcode sector to county.

This study utilised data at postcode sector level, the finest granularity available. UK postcodes follow a hierarchical system (Area, District, Sector, Unit), comprising two alpha-numeric text components separated by a space, a typical example for Northamptonshire being NN1 2AB. The code component before the space, the Outward code, directs mail from the originating sorting office to the destination sorting office, while the component after the space, the Inward code, sorts mail into individual delivery rounds. In the Northamptonshire example, the initial pair of letters of the outward code $(\mathrm{NN})$ represents the Northampton Area, while the following digit or digits represent the District (1, corresponding to the central area of Northampton town) within that area. The first component of the inward code ( 2 in this example, representing part of the central business area) defines the Postcode Sector, which usually contains several thousand individual addresses depending on the locality, with an average area across the UK of $22 \mathrm{~km}^{2}$. The final component, $\mathrm{AB}$ in this example, may represent between ten and twenty residential addresses or a single business address.

In addition to arithmetic and geometric mean radon levels, the Atlas tabulates total numbers of homes in each geographical unit with the corresponding number of homes tested for radon, and projects the percentage of homes anticipated to show mean annual radon concentration levels exceeding the UK Action Level of $200 \mathrm{~Bq} \cdot \mathrm{m}^{-3}$. For confidentiality, the Atlas does not publish data for areas where few $(<10)$ measurements have been made. To further improve the estimates of average radon concentration, only postcode sectors where at least 50 houses had been tested were considered here, reducing the potentially usable dataset to around $50 \%$ of the total housing tested for radon in England and Wales.

Using the published data, each postcode sector reporting results from 50 or more radon measurements was assigned to one of nine radon bands, defined by the percentage of homes in that sector with radon levels above the $200 \mathrm{~Bq} \cdot \mathrm{m}^{-3}$ Action Level. Band 1 contained postcode sectors with between 0 and $1 \%$ of measured homes with radon concentrations above the Action Level. Bands 2 to 9 correspond to the RAAs (NRPB, 1990). Table 1 summarises the radon band allocations, together with the corresponding numbers of houses tested and the annual mean radon concentration for each band, weighted to compensate for the numbers of homes in each postcode sector. Geographically, the radon bands represent groups of spatially-distributed, potentially discontinuous areas, chosen to ensure approximately equal sample size in each of the nine groups. All postcode sectors represented in the THIN database but not appearing in the Radon Atlas, along with all sectors appearing in the Radon Atlas but with less than 50 radon measurements, were allocated to Band 0; incomplete data records were allocated to a further Band 10, the contents of which $(68,066$ records comprising $2.82 \%$ of the total $20,137,547$ person-years encompassed by the

\footnotetext{
${ }^{5}$ FDB, Swallowtail Road, Exeter, Devon EX1 3LH, UK
} 
study) were discarded in subsequent analysis. Figure 2, generated using the open-source mapping software QGIS (2015), indicates the geographical spread of the radon bands on a map of British postcode sectors.

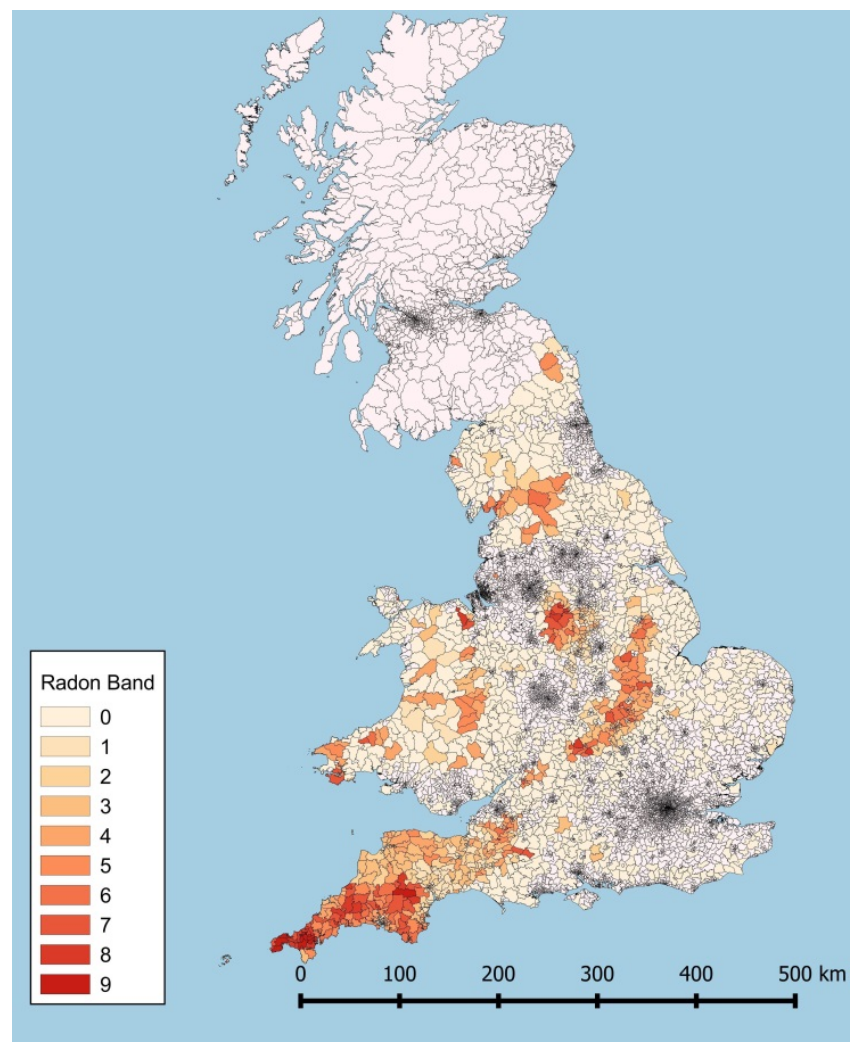

Figure 2: Geographical distribution of postcode sectors comprising Radon Bands $0-9$. Contains Ordnance Survey data (C) Crown copyright and database right 2012. Contains Royal Mail data (C) Royal Mail copyright and database right 2012. Contains National Statistics data (C) Crown copyright and database right 2012.

\subsubsection{Case Identification}

The resultant dataset was interrogated to extract the numbers of patients diagnosed with MS (numerator population) and total patient numbers (denominator population). The principal clinical search criteria, listed in Table 2, were Read Code F20, its subsidiaries and a further set of related codes. To ensure that any relevant radon exposure was received in the patient's current home, and assuming that radon-induced MS initiation might replicate radon-induced lung-cancer, characterised by a linear-no-threshold process (BEIR, 1999; Darby et al., 2005) with latency period of the order of five years (Field et al., 2000), interrogation was limited to those patients with at least five years of registration history with the same general practice before first diagnosis.

Data interrogation was carried out for England and Wales separately for each year of the period 2005 to 2012 individually, with output presented as annual country-specific tables of incidence for males and females, classified by radon band and age. To generate a sufficiently large population for reliable subsequent statistical analysis, the results from these eight years and from the two geographic entities were combined. Modelling based on the known geographic incidence of environmental radon gas, the variation of lung-cancer incidence with radon, and the relative overall incidence figures for lung-cancer and MS, suggested that the study might identify 156 new MS diagnoses in RAAs during the eight-year period. 


\section{Results}

\subsection{Study Population}

The study population was defined as those individuals identified from their residential address as living in a postcode sector situated in one of the radon bands defined in Table 1, and whose medical records were held in one of the GP databases participating in THIN. Overall, this represented $20,140,498$ person years of clinical monitoring, distributed approximately equally between males (10,056,628: 49.93\%) and females (10,083,870: 50.07\%).

Although the Radon Atlas reports the number of homes within each geographical measurement unit, no data are available in this source regarding populations in each area. Assuming average household size of 2.47 across England and Wales (ONS, 2011), Figure 3 compares on a band-by-band basis the normalised population derived from the Radon Atlas and the correspondingly normalised THIN base population. Chi-squared testing confirmed $\left(\chi^{2}>0.99\right)$ these distributions to be essentially identical.

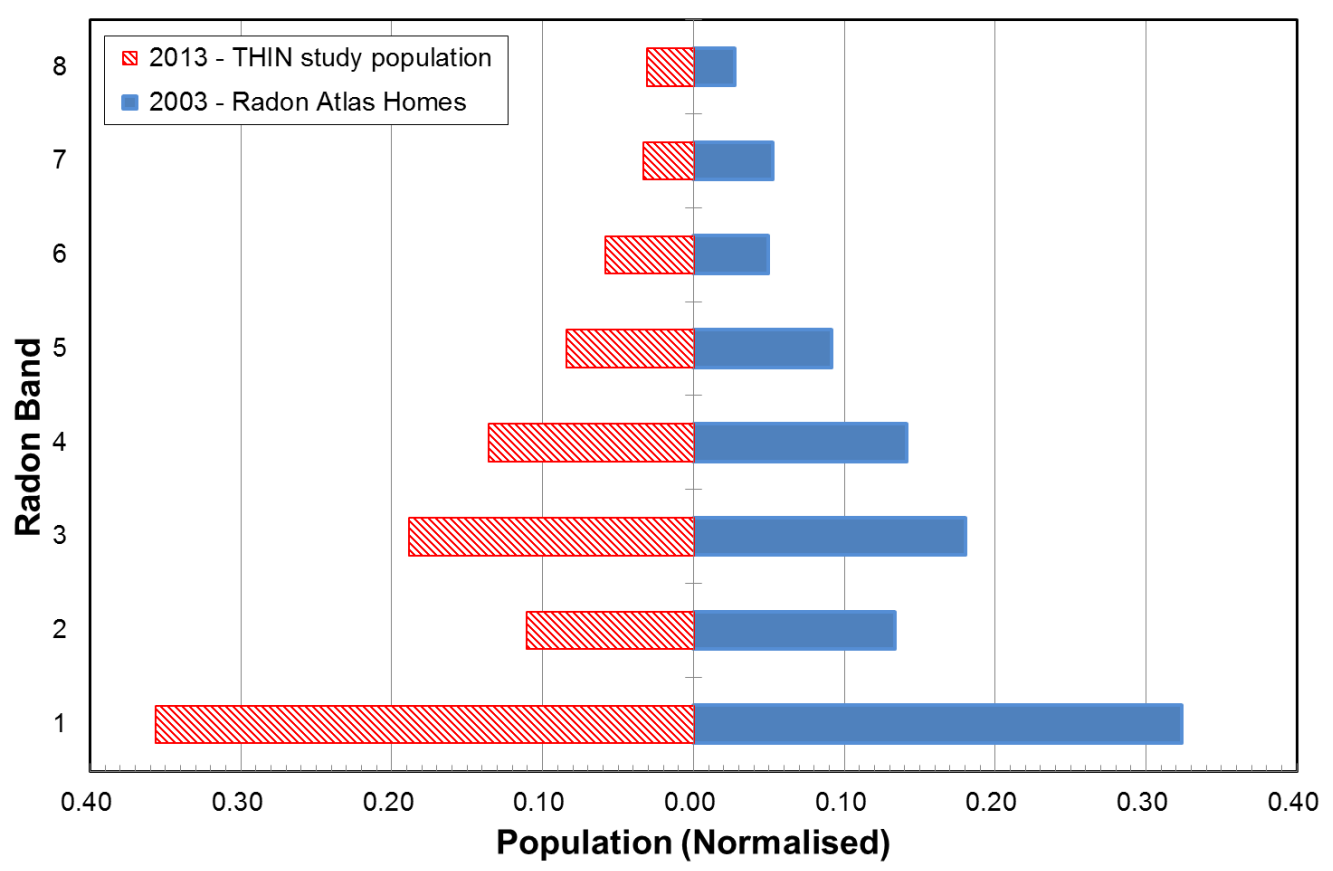

Figure 3: Population profiles of radon bands

Hatched bars - THIN base population

Solid bars - homes tabulated in Radon Atlas

Using standard age-bands, Figure 4 compares the normalised age profile within the base population with the corresponding age profile of the population of England and Wales (E\&W) in the year 2010 (ONS, 2011). While the five-year registration condition inevitably makes direct comparison difficult, the reduced presence of individuals aged 20 - 30 years in the extracted data, possibly due to the additional mobility of this age group, which encompasses students and young adults taking up their first employment, deserves notice and highlights the need for care in comparisons. 


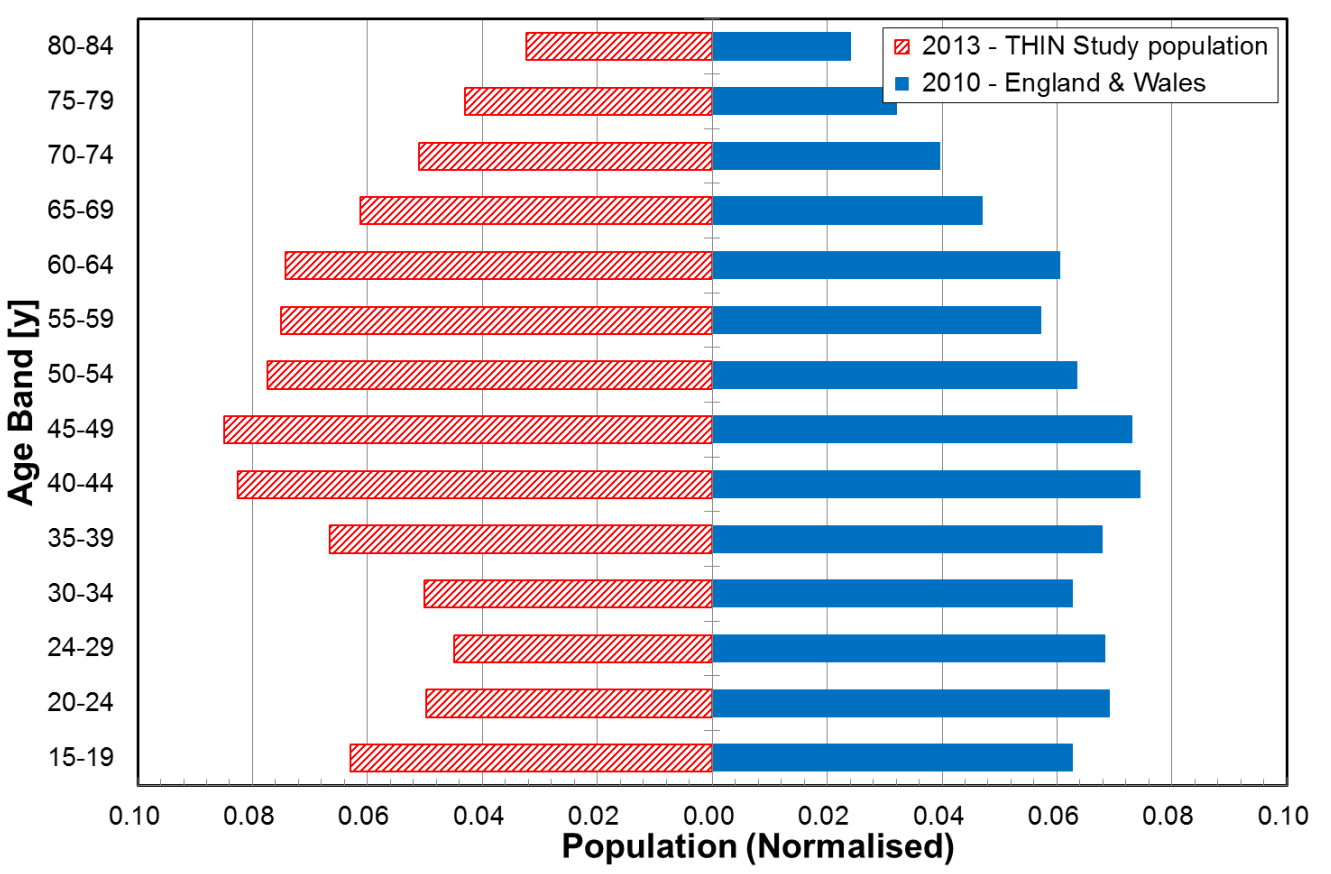

Figure 4: Age profiles of populations

Hatched bars - THIN base population

Solid bars - England and Wales (mid-2010) (ONS, 2011)

\subsection{Raw MS Incidence}

A total of 1,512 new MS cases were diagnosed, from a mean annual population of around 2.5 million people. Females (1,070 cases) outnumbered males (442 cases) by a factor of 2.42 , comparable with the factor of 2.38 found by Mackenzie et al. (2014) in their recent review of MS incidence in the UK. Of the 1,512 new cases, just 115 could be allocated to one of the radon bands representing RAAs, compared with the 156 expected from the modelling referred to above.

Using corresponding data for MS diagnoses (numerators) and source population (denominators), raw incidence rates (population fraction diagnosed with MS per $10^{5}$ person-years) were derived for each year/patient-age/radon-band locus. Table 3 summarises the raw output data aggregated over the study period for England and Wales combined, presenting MS incidence and underlying population for males, females and the total population. Results for the full population, Table 3(a), and for the subset of validated residents of the radon bands, Table 3(b), are shown separately.

Raw incidence rates among the overall population were 10.61 and 4.40 per $10^{5}$ person-years for females and males respectively, with an overall population incidence of 7.51 per $10^{5}$ person-years. Among the validated residents of radon band areas, the corresponding figures were 11.30 and 4.67 per $10^{5}$ person-years for females and males respectively, with an overall population incidence of 7.89 per $10^{5}$ person-years. These are, respectively, $6.60 \%, 4.54 \%$ and $5.05 \%$ greater than the figures from the base population. Raw incidence data from the base population (Table 3(a)) are shown graphically in Figure 5. The distribution of incidence across the age-bands and between the genders is comparable in form with that found nationally in previous studies (Bray, 2002; Mackenzie et al., 2014). 


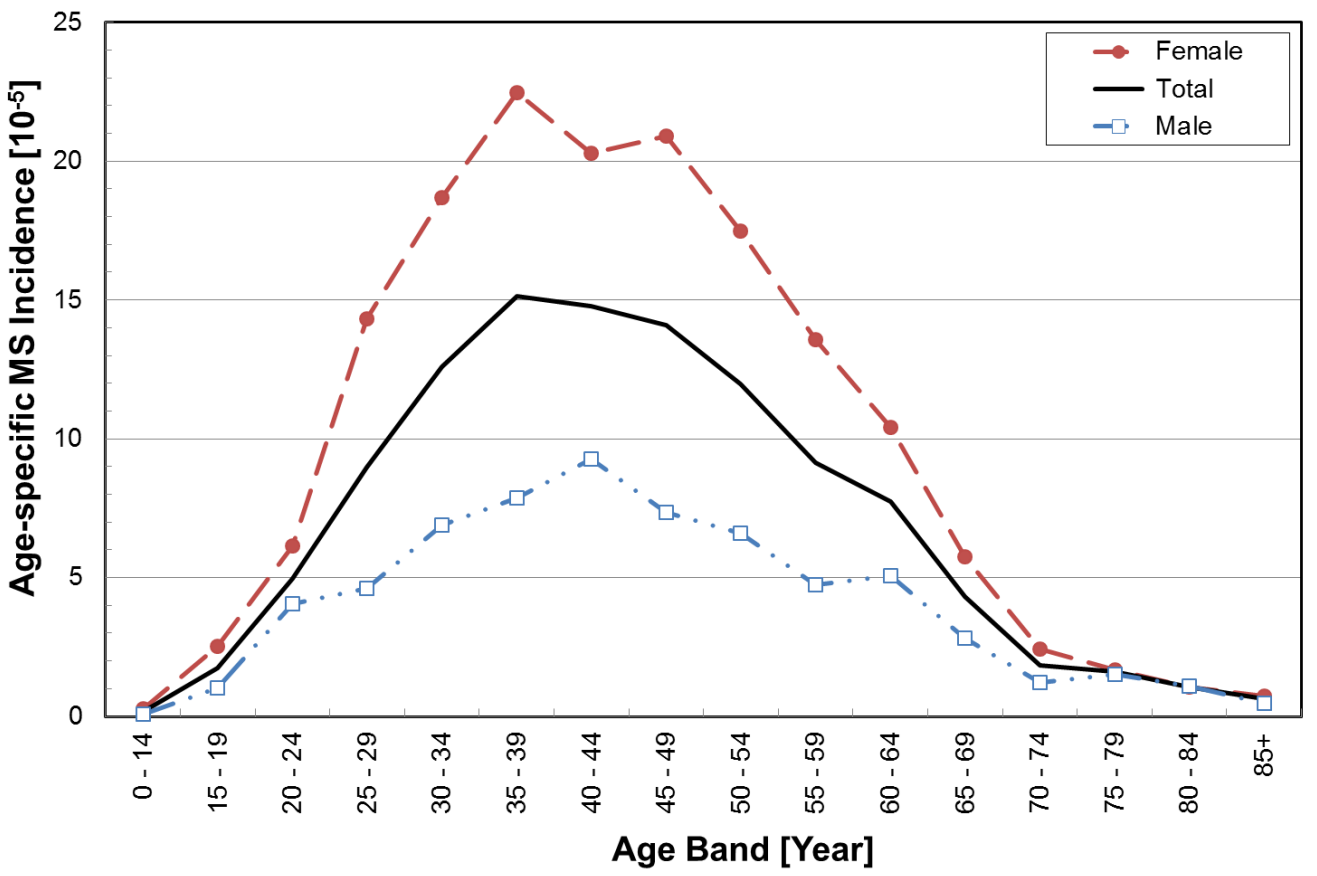

Figure 5: Age distribution of MS incidence among the full study population (Bands 0 - 9)

Dashed line/solid circles (red):

Female

Chain line/open squares (blue):

Male

Continuous line (black)

Full population

Raw MS incidence was standardised to both the 2010 England and Wales Population (Bray, 2002) allowing comparison with previous MS incidence studies in these countries, and to the Standard World Population (Segi, 1960), facilitating comparison with international studies. Standardising to the 2010 England and Wales population gives incidence of 11.43 per $10^{5}$ person-years for females, 4.88 per $10^{5}$ person-years for males and 8.12 per $10^{5}$ person-years overall. As Table 4 shows, these results show good agreement with those of a recent evaluation of MS incidence in the UK over the period 1990 to 2010 (Mackenzie at al., 2014); this utilised the GPRD (Walley and Mantagini, 1997), an alternative extraction of GP records, with coverage comparable to that of THIN. Both studies show higher incidence than those obtained by Alonso et al. (2007) in their UK investigation covering the period 1993 to 2010, again using the GPRD.

\subsection{MS Incidence and Radon Concentration Level}

Table 3 summarises the identified cases and corresponding base populations, by individual radon band, along with overall population estimates derived from the Radon Atlas and assuming a mean household occupancy of 2.47. With the exception of Band 9, which encompassed just 14 personyears and returned no new MS diagnoses during the study period, the proportion of the Radon Atlas population sampled by THIN was moderately consistent, ranging from $2.35 \%$ to $4.31 \%$.

Using both raw and population-corrected data, MS incidence rates were determined for each radon band. Results are summarised in Table 6 for males and females separately and together, by radon band over the eligible population, and totalled for England and Wales. In addition to the raw data, incidence standardised to the ONS 2010 and World Standard populations is also tabulated.

\section{Analysis of Results}

As discussed above, meta-analysis of an expanding portfolio of epidemiological studies indicates that the ERR of radon-induced lung-cancer exhibits linear-no-threshold dependence on mean radon 
exposure of the exposed population. If radon has a triggering role in the development of MS, then correlation might reasonably be assumed to exist between the incidence of the condition and the radon concentration level experienced by the exposed population, similar to that observed to exist between radon and lung-cancer.

Using incidence data standardised to the ONS 2010 population (Table 6), ERR for MS due to radon exposure was calculated for each radon band, taking mean incidence for the full THIN population as normalising parameter. Results are plotted in Figure 6 (solid line). As the figure shows, no simple monotonic relationship exists between ERR and radon concentration; indeed Band 1, which has the lowest average radon level, exhibits relatively high MS incidence and ERR. The observed scatter is attributed to the small sample size.

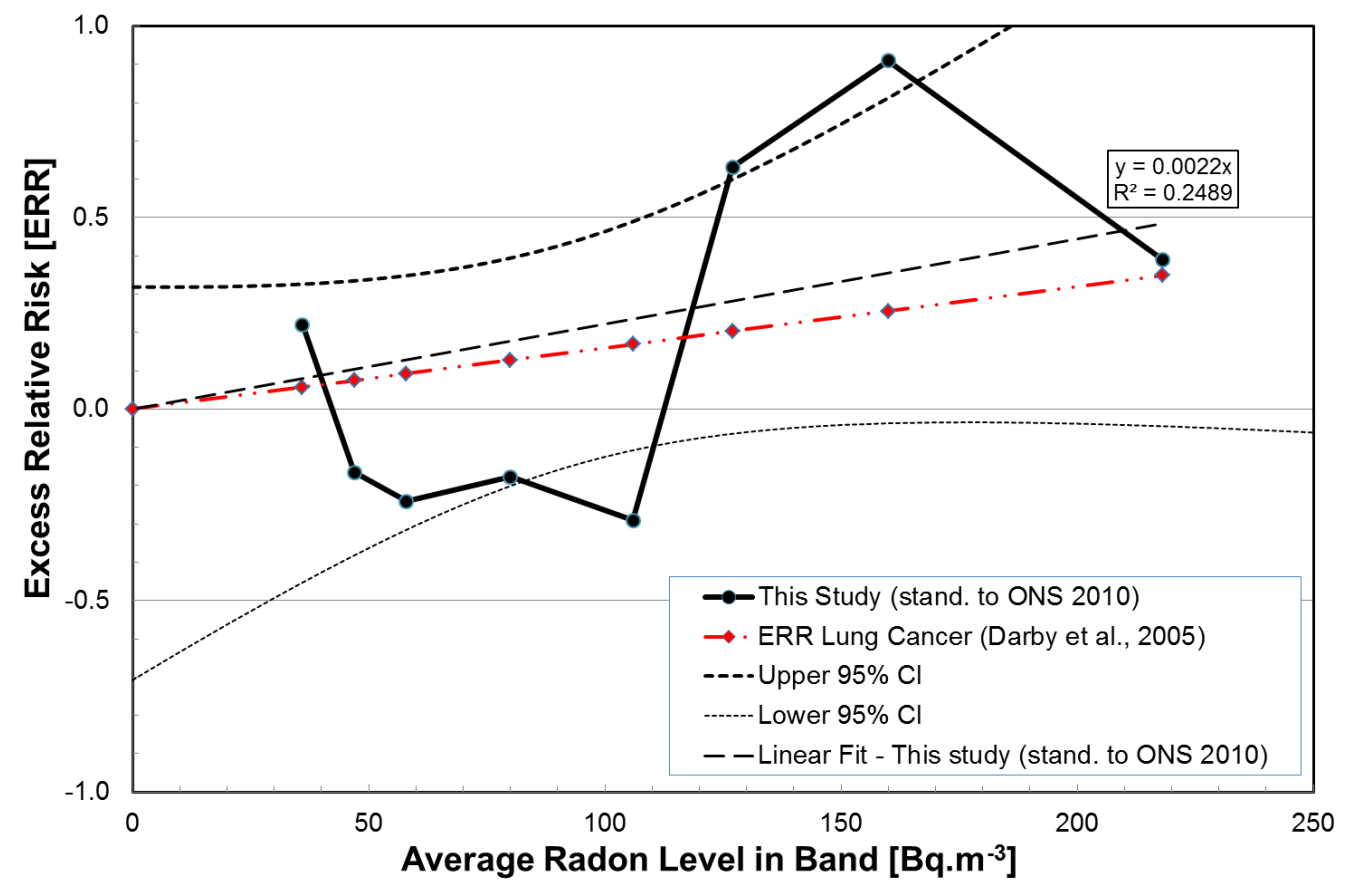

Figure 6: Excess relative risk for MS (standardised to England and Wales 2010 population) by radon band

Heavy continuous line/circles (black): Experimental results from this study

Light continuous line (black):

Light dashed lines (black):

Linear fit from this study

Heavy chain-dashed line/diamonds (red): ERR vs radon for lung-cancer

(Darby et al., 2005)

Linear regression of ERR against mean radon, plotted as the dashed black line in the figure, shows a positive gradient of 0.22 per $100 \mathrm{~Bq} \cdot \mathrm{m}^{-3}$ when forced to pass through the origin (representing a linear-no-threshold response), and $0.44 \mathrm{per} 100 \mathrm{~Bq} \cdot \mathrm{m}^{-3}$ when unconstrained. The experimental data exhibit wide scatter $\left(R^{2}=0.25, p=0.0961\right)$ and the fit is not statistically significant at $95 \%$

Confidence Interval. Statistical significance was not achieved by relaxing the criterion to $90 \%$. Note that the line of best fit, the null hypothesis represented by the $x$-axis $(\mathrm{y}=0)$ and the linear increase expected for radon-induced lung-cancer from the European case-studies (Darby et al., 2005) (chaindashed red line, 0.16 per $100 \mathrm{~Bq} \cdot \mathrm{m}^{-3}$ ) all lie inside the $95 \%$ Confidence Interval of the linear regression (Liengme, 2015) (light dotted hyperbolae).

Pearson's Chi-squared test was used to compare MS cases in the minimal radon band (Band 1: 44 cases in 505,566 patient-years) with those for RAAs (Bands 2 to 9: 71 cases in 911,199 patient- 
years), yielding $\chi^{2}$ for the null hypothesis of 0.632 with continuity correction, 0.564 without continuity correction, and the difference in incidence between Band 1 and Bands 2 to 9 is therefore not statistically significant. Similar results were obtained when comparing males and females separately.

The methodology employed here provides estimates of overall MS incidence similar to those provided by previous studies (Alonso et al., 2007; Mackenzie et al., 2014), as shown in Table 4. However, although the geographical spread of postcode sectors within each radon band contributes to ensuring that local non-uniformities of coverage are averaged on a band-by-band basis, the relatively low and non-uniform patient coverage by THIN in England and Wales (Table 5) ensures that insufficient data are currently available to confirm or refute the hypothesised correlation between MS incidence and radon concentration statistical significance.

\section{Discussion}

\subsection{Study Design}

Domestic radon concentrations can exhibit extreme variability over relatively short geographical ranges, and these variations tend to be smoothed out as the size of the sampled locale increases. In the UK, domestic radon concentration levels are now known with high geographical resolution, the Radon Atlas for England and Wales providing data at the level of postcode sector, the average area of which is $22 \mathrm{~km}^{2}$. While this development, together with the advent of large computerised anonymised databases has facilitated the present investigation of the association between radon and MS incidence, the definitive demonstration of such an association would comprise a longitudinal case-control study, measuring radon in the homes of individual MS patients and controls and modelling their exposure, especially if they had previously moved house. This could be a complex, lengthy and expensive process, which might need to be international in scope and collaboration to recruit sufficient participants.

A prime aim of the present study was to improve on the sensitivity of previous studies by directly accessing patient records in order to establish diagnoses, central to this objective being (a) the precision of diagnosis and recording into clinical notes by GPs and specialists and (b) the representative nature of the database derived from these notes and other data. Mackenzie et al. (2014) addressed the second of these issues, noting that a major strength of using an extraction database such as THIN is that it covers a representative sample of GPs, spread geographically, with a patient population broadly representative of that of the country as a whole. The present study population, 2.5 million patients tracked across a time-span of 8 years, provides greater statistical precision than that achievable through a regional survey, such as that recently reported by Neuberger et al. (2011).

In addition to THIN, two further data extraction systems are in use in the UK. GPRD (now subsumed into Clinical Practice Datalink (CPRD) with an expanded source base) also interrogates Vision 360 systems, some practices contributing to both THIN and CPRD. QResearch (HippisleyCox et al., 2004), formed as a partnership between EMIS and Nottingham University, accesses EMIS-based practices, around $50 \%$ of the UK total. Neither of these approaches full coverage of the clinical population, with both appearing to access comparable patient numbers to THIN.

The representative nature of THIN data has been evaluated independently by comparing observed demographics, chronic condition prevalence, deprivation and deaths with UK national estimates (Blak et al., 2011), confirming that THIN can be generalised to the UK in terms of demographics and crude prevalence of major conditions, and that data collected outside GPRD appear as valid as the data collected within it (Herrett et al., 2010; Lewis et al., 2007). The principal weakness in the present methodology is the low penetration of data extraction from UK GP records, since the study 
population results from the intersection of the two sparsely-populated geographical distributions, the RAAs and the extracted practices. Modelling of the penetration prior to commencement of the study failed to project the lack of patients in Band 9 (Cornwall), despite the relatively uniform distribution across the remainder of England and Wales. Although more radon results would improve the RAA mapping, the most important factor currently restricting the power of this analysis is the modest percentage of the population accessed by THIN.

The Health and Social Care Act 2012 requires GP practices to provide information to the Health and Social Care Information Centre in specified circumstances, and authorises NHS England, the body responsible for managing public health services in England, to extract this data, along with data collected by the Hospital Episodes Statistics service, to provide an integrated data service, known as Care.Data. This builds on existing data services, linking GP and hospital records for the first time, eventually expanding to cover all care settings, both in and outside of hospital, and will extract data from all GP databases, not just from those choosing to opt in to an existing proprietary scheme. Although currently in its pilot phase, eventual full nationwide roll-out is anticipated to provide a future opportunity to repeat this study with a database potentially 20 times larger than that explored here, with correspondingly enhanced statistical confidence.

\subsection{Confounding Factors}

In interpreting the study results, a number of potential confounding factors require consideration.

\subsubsection{Vitamin $D$ and Exposure to Sunlight}

There is clear evidence that reduced exposure to sunlight, and the consequent lack of vitamin D, increases MS risk. Meta-analysis of 321 studies (Simpson et al., 2011) found significant positive association (change in prevalence per degree-latitude) between age-standardised prevalence (1.04, $p<0.001)$ and latitude, diminishing at high latitudes; adjustment for prevalence year strengthened the association with latitude $(2.60, p<0.001)$. The persistence of a positive gradient in Europe after adjustment for HLA-DRB1 allele frequencies strongly supports a role for latitude-dependent environmental factors, the most prominent candidates being ultraviolet-B (UV-B) radiation and Vitamin D. Mackenzie et al. (2014) note (a) that significant $(\mathrm{p}<0.001)$ variations in incidence and prevalence exist between different regions of the UK and (b) that, despite the difference in MS incidence between Scotland and the England, no statistically significant trend with latitude exists within the twelve English regions.

Using a publicly-accessible tabulation of postcode coordinates ${ }^{6}$, the geographical centroids of the sets of postcode sectors comprising the individual radon bands were determined, a further publiclyaccessible data tool $^{7}$ being used to model the mean annual UV-B irradiation at each band centroid. Bands 1 to 7 have relatively wide spatial distribution, standard deviations for latitude and longitude of their sets of postcode sector centroids being around 1.2 and 1.4 degrees $(132 \mathrm{~km}$ and $94 \mathrm{~km}$ at latitude 52 degrees) respectively. Band 8 is largely (18 of 27 sectors) located in south-west England, with the remainder located in Oxfordshire (two sectors) and the Peak District (seven sectors), and Band 9 (contributing no MS cases to the study) is entirely so, with significantly smaller centroid standard deviations. Geographical centroids of the bands migrate in a consistent south-westerly direction from Gloucester (Band 1) to Lynmouth, Devon (Band 8) and to Redruth, Cornwall (Band 9) a distance of approximately $300 \mathrm{~km}$. Along this track, annual UV-B irradiation increases linearly $\left(R^{2}=0.81\right)$ from $27.7 \mathrm{~kJ} \cdot \mathrm{m}^{-2}$ in Band 1 to $31.0 \mathrm{~kJ} \cdot \mathrm{m}^{-2}$ in Band 9 . Bands 1 to 7 show reduced

\footnotetext{
${ }^{6}$ PostcodePal - Database Generator: Vulcan Logix UK Ltd, 145-157 St. John Street, London EC1V 4PW, UK. Online at http://www.postcodepal.com/?page=database-generator

${ }^{7}$ SoDa - Integration and exploitation of networked solar radiation databases for environment monitoring. European Commission, Contract IST-1999-12245 (2000 - 2003). Calculation tool online at http://www.soda-is.com.
} 
UV-B irradiation range of $27.7-28.4 \mathrm{~kJ} \cdot \mathrm{m}^{-2}$; for the present study, therefore, UV-B irradiation can be regarded as geographically invariant except over the limited area encompassed by Bands 8 and 9 , and can be discounted as a first order confounding factor.

In addition to the general latitudinal UV exposure gradient, variation in time spent indoors, sunbathing, use of tanning studios and vitamin pill consumption will affect individual vitamin $\mathrm{D}$ levels. Increased time indoors will also increase overall radon dose, and it has been postulated that, if a link to radon exposure exists, this might explain increased MS incidence in women (Eidbo and Prater, 2004). At the level of the present study, however, these effects could not be quantified and a countrywide uniformity was therefore assumed.

\subsubsection{Tobacco Smoking}

Recent reviews confirm association between cigarette smoking and MS onset, with ERR of $0.4-0.8$ among smokers (Hedstromm et al., 2013; Jafari and Hintzen, 2011; Wingerchuk, 2012). In England, smoking prevalence is highest in the major conurbations (London, Manchester, Liverpool and Leeds-Bradford), all predominantly low-radon areas in Bands 0 and 1. Denman et al. (2014) analysed smoking prevalence and the percentage of houses above the radon action level in English local authorities, reporting no correlation between these parameters $(R=-0.05)$. Since similar geographical considerations apply with regard to tobacco smoking as to UV exposure, it is anticipated that, given the widespread distribution of postcode sectors within each radon band, geographical variations in smoking prevalence can be disregarded in the present analysis.

\subsubsection{Physical Trauma}

It has long been felt that physical trauma, particularly involving the spinal cord and/or the brain, could disrupt the blood-brain barrier, leading to the development of MS plaques in those who are already genetically at risk (Poser, 2000). In a recent meta-analysis (Lunny et al., 2013) of 36 highquality case-control studies and four cohort studies, the former indicated statistically significant association between premorbid head trauma and risk for developing MS. With one exception, where significant brain injury within the last six years was reported to double MS incidence (Kang et al., 2012), this correlation was absent in the cohort studies. Although interactions of this nature were not sought in this study, it is anticipated that their incidence would be relatively low and will not significantly influence the results.

\subsubsection{Ethnicity and Social Deprivation}

Although Ramagopalan et al. (2010) noted that studies controlling for confounding factors, e.g. the US Veterans series (Kurtzke et al., 1979), showed lower MS prevalence in a number of nonCaucasian races/nationalities, recent studies in the USA (Langer-Gould et al., 2013) question the widely accepted assertion that black males have a lower risk of MS than whites. In England and Wales, immigrant non-Caucasian ethnic groups have historically concentrated in cities where, as already noted, radon levels are generally low (Bands 0 and 1), where the 50-measurement criterion excludes many postcode sectors from analysis (Band 0 ), and where genetic disposition to MS is below average (Hedstrom et al., 2013). Ramagopalan et al. (2011) observe that the pattern of UV-B and MS is confounded in large metropolitan areas (Merseyside, Manchester, Leeds, Birmingham and London), geographically-weighted regression showing these regions to be two standard deviations below the main trend.

The Database Managers report (Blak et al., 2011) that THIN has a higher proportion of patients living in the most affluent areas than the national average, with $23.5 \%$ of its subjects resident in the least deprived Townsend quintile (Townsend et al., 1988). This is likely to be related to deprivation in inner cities which, as discussed, tend to exhibit low radon levels and therefore contribute minimally to the results presented here. 
No bias is therefore expected from either of these confounders.

\subsubsection{Radon Band Allocation}

While the Radon Atlas gave values for the average radon level in postcode sectors where 10 or more houses had been tested, the study protocol only collected data from postcode sectors where more than 50 houses had been tested. This ensured that the calculated average radon level for the postcode was more closely indicative of the actual average of the sector.

A consequence of the study protocol was that residents of homes where radon remediation had already been carried out, and where radon levels had consequently been reduced, could not be corrected for or excluded from consideration. The HPA confirm ${ }^{8}$ that radon concentrations reported in the various Radon Atlases represent the first measurement from each house tested; in the vast majority of cases, these can therefore be assumed to represent the situation prior to any remediation that might have been carried out. Since remediated houses have lower radon concentrations than unremediated houses, the cumulative radon exposure for any radon band where some patients lived in remediated houses would therefore be expected to be less than that derived from calculating the exposure from the mean of the radon levels in each postcode sector.

However, response to successive campaigns to test and remediate homes has been modest, at best. Only $40 \%$ of householders in the original RAAs have had their homes tested, and of those finding radon levels exceeding the Action Level, only 15\% have taken remedial action (Denman et al., 2013). In Band 9, where 50\% of homes exceed the Action Level, this represents just 3\% of all houses, while for Band 8 , it is $1.8 \%$. For Bands 7 and below, the maximum percentage of houses remediated is below $1 \%$. It is therefore unlikely that this effect will significantly influence the results.

\subsubsection{Population Mobility}

On average, during the period covered by the study data, $46 \%$ of the UK population lived in the same house for over 15 years and 25\% for more than 30 years (DCLG, 2009). Conversely, 35\% of the population moved house within five years, although $60 \%$ of movers stayed within a five-mile radius of their last property and $23 \%$ moved less than one mile. Even this restricted mobility, however, can potentially confound the analysis since, as noted above, the causative exposure for radon-induced lung-cancer could be up to five years before disease onset. The study population was therefore restricted to patients registered at their GP practice for at least five years prior to the commencement of the analysis period. While this condition necessarily impacts patient numbers in the more-mobile 20 - 30 year age group, population standardisation effectively compensates for this. It should be noted that this criterion does not exclude patients who moved home, but remained registered with their original GP.

The similarity of this study's estimate of overall MS incidence to those of previous UK studies (Alonso et al., 2007; Mackenzie et al., 2014) (c.f. Table 4) suggests that using a population subset with lower mobility has not introduced any bias.

\section{Conclusions}

Although attention has hitherto been focussed on environmental radon gas in the context of its causative role in lung-cancer, a growing body of evidence suggests that radon may be implicated in the initiation of other conditions, recent studies indicating a possible causative link between elevated levels of environmental (particularly domestic) radon gas and increased MS incidence. To test this hypothesis, a retrospective study was performed of MS incidence among the population of

\footnotetext{
${ }^{8}$ Private communication to CJGK, 2005
} 
England and Wales resident in those areas of elevated domestic radon concentration classified as Radon Affected Areas (RAAs), using the clinical extraction database maintained by The Health Improvement Network (THIN). This contains the electronic medical records of 12.4 million patients (3.6 million active patients) equivalent to 75.6 million patient years of data collected from 587 general practices in the UK, covering $5.7 \%$ of the UK population.

The study population, 20,140,498 person-years of clinical monitoring, represents a mean annual population over the eight-year study period of around 2.5 million individuals, equally divided between males and females. During this period, 1,512 new MS cases were diagnosed, females ( 1,065 cases) outnumbering males ( 441 cases) by nearly 2.5 times, equivalent to raw incidence rates of $7.51,10.61$ and 4.40 per $10^{5}$ person-years respectively, comparable to previous studies.

Of the 1,512 new cases, 115 were reliably allocated to one of the radon bands representing areas located in RAAs. Standardising raw data to the 2010 England and Wales age profile, ERR figures for MS were calculated for each radon band, using the mean MS incidence for the full population as normalising parameter. No simple monotonic relationship is apparent between MS incidence and radon concentration and the data exhibit wide scatter $\left(R^{2}=0.25\right)$. Linear regression of ERR against mean band radon concentration shows a positive gradient of 0.22 per $100 \mathrm{~Bq} \cdot \mathrm{m}^{-3}$ when forced to the origin (representing linear-no-threshold response), comparable to that reported for lung-cancer $(0.16$ per $100 \mathrm{~Bq} \cdot \mathrm{m}^{-3}$ (Darby et al., 2005) and hinting at a possible common mechanism for the triggering process. Most of the plotted points fall between the $95 \%$ Confidence Limits for the linear fit, as also do the null hypothesis represented by the $x$-axis $(y=0.0)$ and the linear increase expected for radoninduced lung-cancer, and although a trend of increasing MS incidence with increasing radon concentration has been identified, the correlation is not statistically significant.

On the basis of the evidence available, and despite the geographical spread of postcode sectors within each radon band, the relatively low and non-uniform patient coverage by THIN renders insufficient data available for a statistically significant conclusion to be drawn, and the hypothesis that mean radon concentration in a RAA is a predictor of the incidence of MS is consequently not proven. It is anticipated that the forthcoming Care.Data service, linking GP and hospital records with universal scope, will provide a future opportunity to repeat this study with a database significantly larger than that explored here, with correspondingly enhanced statistical power.

As noted above, the definitive demonstration of association between radon and MS incidence would comprise a longitudinal case-control study, measuring radon in the homes of individual MS patients and controls. This might need to be international in scope and collaboration to recruit sufficient participants. Our study may not have generated a sufficiently interesting result to justify such a major investigation, but it does justify further repeat investigations, either using a larger UK patient database, or considering regions with higher indoor radon levels.

Numerous campaigns to monitor domestic radon levels, and to encourage remediation where high levels are discovered, have been undertaken, the prime motivation being the reduction in the overall population risk of lung-cancer. However, the response to these campaigns to date has been moderate, with positive action being generally greatest among the sections of the population least at risk of lung-cancer. Recognition of the linkage between radon and other conditions contributing significantly to the overall health burden has the potential to bring additional, hitherto unrecognised, health benefits, with the associated publicity potentially increasing the likelihood of the public taking action to reduce domestic radon levels and making remediation campaigns correspondingly more cost-effective.

Finally, although a limited number of ecological studies on MS have been reported, no similar investigations appear yet to have been undertaken on the other neurological conditions in which 
radon has previously been incriminated, viz. Alzheimer's and Parkinson's diseases and motor neurone disease. With radon concentration data for England, Wales, Northern Ireland and much of Scotland now becoming available at increasing geographical resolution, and with the increasing availability of integrated clinical data record systems such as THIN, CPRD and, imminently, Care.Data, the opportunity now presents itself to initiate further studies of this nature.

\section{Ethics}

Ethical approval for the present study, under the title "Is Naturally Occurring Radon Gas an Environmental Risk Factor for Multiple Sclerosis? - A Pilot Study", Ref Number R13-024, was granted by THIN Scientific Review Committee on 17th September 2013.

\section{Acknowledgements}

The authors are grateful to the staff of Cegedim Strategic Data (now IMS Health), particularly Mary Thompson and Richard Derrick, for their helpful discussions and their assistance in defining the search parameters.

We wish to acknowledge receipt of a research grant from the University of Northampton and additional financial support from NHS Northamptonshire.

Finally, we wish to thank the Referees for their thorough reviews and for their useful and constructive comments on the original manuscript.

\section{Conflicting Interests}

There are no conflicting interests.

\section{References}

AGIR (Advisory Group on Ionising Radiation) (2009). Radon and Public Health. Documents of the Health Protection Agency RCE-11. ISBN: 978-0-85951-644-0.

Alonso A, Jick SS, Olek MJ, Hernán MA (2007). Incidence of multiple sclerosis in the United Kingdom - Findings from a population-based cohort. J. Neurology 254:1736-1741. doi 10.1007/s00415-007-0602-z.

Axelson O, Landtblom A-M, Flodin U (2001). Multiple sclerosis and ionizing radiation. Neuroepidemiology 20:175-178. doi: 10.1159/000054784.

BEIR VI (Committee on Health Risks of Exposure to Radon) (1999). Health risks of exposure to radon. Washington DC, USA: National Academy Press.

BGS (British Geological Survey) (2015). Make-a-Map. Online at http://www.bgs.ac.uk/discoveringGeology/geologyOfBritain/makeamap/home.html. Accessed November 2015.

Belbasis L, Bellou V, Evangelou E, Ioannidis J, Tzoulaki J (2015) Environmental risk factors and Multiple Sclerosis: an umbrella review of systematic reviews and meta-analyses. Lancet Neurol. 14:263-273.

Bentley T, Price C, Brown P (1996). Structural and lexical features of successive versions of the Read Codes. Proc. 1996 Ann. Conf., Primary Health Care Specialist Group, British Computer Society. 
Blak BT, Thompson M, Dattani H, Bourke A (2011). Generalisability of The Health Improvement Network (THIN) database: demographics, chronic disease prevalence and mortality rates. Inform. Prim. Care 19:251-255.

Bourke A, Dattani H, Robinson M (2004). Feasibility study and methodology to create a qualityevaluated database of primary care data. Inform. Prim. Care 12:171-177.

Bray F (2002). Age Standardisation, in Parkin DM, Whelan SL, Ferlay J, Teppo L, Thomas DB (Eds). Cancer Incidence in Five Continents Vol. VIII, International Agency for Research on Cancer: Lyon, 87-89.

Bølviken B, Celius EG, Nilsen R, Strand T (2003). Radon: a possible risk factor in Multiple Sclerosis. Neuroepidemiology 22:87-94. doi: 10.1159/000067102.

Carroll D (2005). An examination of the relationship between the prevalence of multiple sclerosis and the geological environment specifically exposure to indoor radon before the age of 15 years. M.A. Thesis, Institute of Technology, Sligo, Ireland.

Compston A, Coles A (2002). Multiple Sclerosis. The Lancet 359:1221-1231.

Compston A, Ebers G, Lassmann,H, McDonald I, Matthews B, Wekerle H (1998). Symptoms and signs of Multiple Sclerosis. in McAlpine's Multiple Sclerosis, Chaps. 2-4, $3^{\text {rd }}$ Ed. London: Churchill Livingstone.

Cooper RL (1997). Multiple sclerosis: an immune legacy. Med. Hypotheses 49:307-311. doi: 10.1016/S0306-9877(97)90196-1.

Daraktchieva Z, Appleton JD, Rees DM, Adlam KAM, Myers AH, Hodgson SA, McColl NP, Wasson GR, Peake LJ. (2015) Radon in Northern Ireland: Indicative Atlas. PHE-CRCE-017. Chilton: CRCE. ISBN 978-0-85951-764-5.

Darby S, Hill D, Doll R (2001). Radon - a likely carcinogen at all exposures. Ann. Oncol. 12:13411351 .

Darby S, Hill D, Auvinen A, Barros-Dios JM, Baysson H, Bochicchio F, Deo H, Falk R, Forastiere F, Hakama M, Heid I, Kreienbrock L, Kreuzer M, Lagarde F, Mäkeläinen I, Muirhead C, Oberaigner W, Pershagen G, Ruano-Ravina A, Ruosteenoja E, Rosario AS, Tirmarche M, Tomásek L, Whitley E, Wichmann HE, Doll R (2005). Radon in homes and risk of lung cancer: collaborative analysis of individual data from 13 European case-control studies. BMJ 330:223-238. doi: 10.1136/bmj.38308.477650.63.

DCLG (Department for Communities and Local Government) (2009). Survey of English Housing, April-December 2007-08. ISBN: 9781409818250.

Denman AR, Rogers S, Timson K, Phillips PS, Crockett RGM, Groves-Kirkby CJ (2014). Future initiatives to reduce lung cancer incidence in the UK: smoking cessation, radon remediation and the impact of social change. Perspect. Public Health 135:92-101. doi: 10.1177/1757913914522785.

Denman AR, Sinclair J, Phillips PS, Crockett RGM, Groves-Kirkby CJ (2013). The cost effectiveness of radon reduction programmes in domestic housing in England and Wales: the impact of improved radon mapping and housing trends. Environ. Internat. 59:73-85. doi: 10.1016/j.envint.2013.05.012. 
Eidbo WB, Prater MP (1994). Ionising radiation: the long sought environmental 'trigger' for multiple sclerosis? National Multiple Sclerosis Society Annual Conference, San Francisco, Calif. Nov 1994.

Eidbo WB, Prater MP (2004). Linkage, Multiple Sclerosis and ionizing radiation. Medical Veritas 1:272-276. doi: 10.1588/medver.2004.01.00030.

Fennell SG, Mackin GM, Madden JS, McGarry AT, Duffy JT, O’Colmain M, Colgan PA, Pollard D (2002). Radon in Dwellings: the Irish National Radon Survey. Dublin: Radiological Protection Institute of Ireland.

Field RW, Steck DJ, Smith BJ, Brus CP, Fisher EL, Neuburger JS, Platz CE, Robinson RA, Woolson RF, Lynch CF (2000). Residential Radon Gas Exposure and Lung Cancer: The Iowa Radon Lung Cancer Study. Am. J. Epidemiology 151:1091-1102.

Forbes R, Swingler R (1999). Estimating the prevalence of multiple sclerosis in the United Kingdom using capture-recapture methodology. Am. J. Epidemiology 149:1016-1024. doi: 10.1093/oxfordjournals.aje.a009746.

Gilmore M, Grennan E (2003). A pilot study of the relationship between Multiple Sclerosis and the physical environment in northwest Ireland. Envir. Geochem. Health 25:157-163.

Green BMR, Miles JCH, Bradley EJ, Rees DM (2002). Radon Atlas of England and Wales. NRPB Report NRPB W-26. Didcot, NRPB.

Gunning GA, Pollard D, Finch EC (2014). An outdoor radon survey and minimizing the uncertainties in low level measurements using CR-39 detectors. J. Radiat. Prot. 34:457-467. doi: 10.1088/0952-4746/34/2/457.

Hedström AK, Hillert J, Olsson T, Alfredsson L (2013). Smoking and multiple sclerosis susceptibility. Eur. J. Epidemiol. 28:867-874. doi: 10.1007/s10654-013-9853-4.

Herrett E, Thomas SL, Schoonen WM (2010). Validation and validity of diagnoses in the General Practice Research Database: a systematic review. Brit. J. Clin. Prac. 69:4-14. doi: 10.1111/j.1365-2125.2009.03537.x.

Hippisley-Cox J, Stables D, Pringle M (2004). QRESEARCH: a new general practice database for research. Inform. Prim. Care 12:49-50.

Hodgson JA., Carey S., Scanlon R. (2014) Developing a new National Radon Risk Map. Dublin: Geological Survey of Ireland.

Hursh B, Morken DA, Davis TP, Lovaas A (1965). The fate of radon ingested by man. Health Phys. 11:465-476.

Hystad P, Brauer M, Demers PA, Johnson KC, Setton E, Carvantes-Larioa A, Poplawski K, McFarlane A, Whitehead A, Nicol A-M (2014). Geographic variation in radon and associated lung cancer risk in Canada. Can. J. Public Health 105:e4-e10.

IMS Health (2015). Data: Statistics. On-line at http://csdmruk.cegedim.com/ourdata/statistics.shtml (Accessed November 2015). 
IUPAC (International Union of Pure and Applied Chemistry) (1979). Solubility Data Series Volume 2 - Krypton, Xenon and Radon - Gas Solubilities. Ed. Clever HL. Oxford: Pergamon Press. ISBN 008-022352-4.

Jafari N, Hintzen RQ (2011). The association between cigarette smoking and Multiple Sclerosis. J. Neurol. Sci. 311:78-85. doi: 10.1016/j.jns.2011.09.008.

Kang JH, Keller J, Lin HC (2012). Increased risk of Multiple Sclerosis after traumatic brain injury: a nationwide population-based study. J Neurotrauma 29:90-95. doi: 10.1089/neu.2011.1936.

Knaffl-Lenz E (1912). Beitrag zur biologischen Wirkung der Radiumemanation [Contribution to the biological effect of radium emanation]. Z. Balneologie 5: 403.

Krewski D, Lubin JH, Zielinski JM, Alavanja M, Catalan VS, Field RW, Klotz JB, Létourneau EG, Lynch CF, Lyon JI, Sandler DP, Schoenberg JB, Steck DJ, Stolwijk JA, Weinberg C, Wilcox HB (2005). Residential radon and risk of lung cancer: a combined analysis of 7 North American casecontrol studies. Epidemiology 16:137-145. doi: 10.1097/01.ede.0000152522.80261.e3.

Kurtzke JF (2000). Multiple sclerosis in time and space - geographic clues to cause. J. Neurovirol. 6:S134-S140.

Kurtzke JF, Beebe GW, Norman JE (1979). Epidemiology of multiple sclerosis in U.S. veterans: 1. Race, sex, and geographic distribution. Neurology 29:1228-1235.

Langer-Gould A, Brara SM, Beaber BE, Zhang JL (2013). Incidence of multiple sclerosis in multiple racial and ethnic groups. Neurology 80:1734-1739.

doi: 10.1212/WNL.0b013e3182918cc2.

Lewis JD, Schinnar R, Bilker WB, Wang X, Strom BL (2007). Validation studies of the health improvement network. (THIN) database for pharmacoepidemiology research. Pharmacoepidemiol. Drug Saf. 16:393-401. doi: 10.1002/pds.1335.

Liengme B. Regression Analysis - Confidence Interval of the Line of Best Fit. Online at http://people.stfx.ca/bliengme/exceltips/regressionanalysisconfidence2.htm (accessed 15 Feb 2015).

Lubin JH, Boice JD Jr, Edling C, Hornung RW, Howe GR, Kunz E, Kusiak RA, Morrison HI, Radford EP, Samet JM, Tirmarche M, Woodward A, Yao SX, Pierce DA (1995). Lung cancer in radon-exposed miners and estimation of risk from indoor exposure. J. Natl. Cancer Inst. 87:817827.

Lubin JH, Tomásek L, Edling C, Hornung RW, Howe G, Kunz E, Kusiak RA, Morrison HI, Radford EP, Samet JM, Tirmarche M, Woodward A, Yao SX (1997). Estimating lung cancer mortality from residential radon using data for low exposures of miners. Radiat. Res. 147:126 -134

Lunny CA, Fraser SN, Knopp-Sihota JA (2013). Physical trauma and risk of multiple sclerosis: a systematic review and meta-analysis of observational studies. J. Neurolog. Sci. 336:13-23. doi: 10.1016/j.jns.2013.08.011.

Lykken GI, Magness AT, Momčilović B (2008). Whole body Bi-214 and bedroom radon concentration in Multiple Sclerosis. FASEB Journal. 22:708-709.

Lykken GI, Momčilović B (2003a). Myelin fat storage of environmental radon daughters in the etiology of multiple sclerosis a new approach. Proc. North Dakota Acad. Sci. March, 2003. 
Lykken GI, Momčilović B (2003b). Environmental radon, high energy alpha particle radiation and multiple sclerosis connection revisited. Proc. $48^{\text {th }}$ Annual Meeting of the Health Physics Society, San Diego, 2003.

Lykken, GI, Momčilović B (2006). PD, radon and altered fatty acid concentration. FASEB Journal 20:A128.

Mackenzie IS, Morant SV, Bloomfield GA, MacDonald TM, O'Riordan J (2014). Incidence and prevalence of multiple sclerosis in the UK 1990-2010: a descriptive study in the General Practice Research Database. J. Neurol. Neurosurg. Psychiatry 85:76-84. doi: 10.1136/jnnp-2013-305450.

Miles JCH, Appleton JD, Rees DM, Adlam KAM, Scheib C, Myers AH, Green BMR, McColl NP (2011). Radon: indicative atlas in Scotland. HPA-CRCE-023: ISBN 978-0-85951-701-0.

Miles JCH, Appleton JD, Rees DM, Green BMR, Adlam KAM, Myers AH (2007). Indicative Atlas of Radon in England and Wales. HPA, Didcot. ISBN 978-0-85951-608-2.

Miles JCH, Green BMR, Lomas PS (1996). Radon Affected Areas: England and Wales. Docs NRPB 7 (No. 2).

Momčilović B, Alkhatib HA, Duerre JA, Cooley M, Long WM, Harris TR, Lykken GI (2001). Environmental lead-210 and bismuth-210 accrue selectively in the brain proteins in Alzheimer Disease and brain lipids in Parkinson's Disease. Alzheimer Dis. Assoc. Disord. 15:106-115.

Neilson S, Robinson I, Rose FC (1996). Ecological correlates of motor neurone disease mortality: a hypothesis concerning an epidemiological association with radon gas and gamma exposure. J. Neurol. 243:329.

Neuberger JS, Nazir N, Keighley J, Lynch S (2011). Residential radon exposure and multiple sclerosis: a pilot study. Proc. $21^{\text {st }}$ International Radon Symposium, American Association of Radon Scientists and Technologists, Orlando FL.

NMSS (National Multiple Sclerosis Society) (1994). Client prevalence/census data: US estimated prevalence rate in multiple sclerosis 1994. National Multiple Sclerosis Society. 1994:32.

NRPB (National Radiological Protection Board) (1990). Statement by the National Radiological Protection Board. Limitation of human exposure to radon in homes. Docs. NRPB 1 (No. 4).

NRPB (National Radiological Protection Board) (2000). Health Risks from Radon. Didcot: National Radiological Protection Board. ISBN 0-85951-449-8.

Nussbaum E, Hursh JB (1965). Radon solubility in fatty acids and triglycerides. J. Phys. Chem. 62:81-84.

ONS (UK Office for National Statistics).(2011). http://www.ons.gov.uk/ons/rel/popestimate/population-estimates-for-uk--england-and-wales--scotland-and-northern-ireland/mid-2010population-estimates/index.html.

Pavia M, Bianco A, Pileggi C, Angelillo IF (2003). Meta-analysis of residential exposure to radon gas and lung cancer. Bull. WHO 81:732-738.

Peterson K, Rosenblum MK, Powers JM, Alvord E, Walker RW, Posner JB (1993). Effect of brain irradiation on demyelinating lesions. Neurology 43:2105-2112. 
Poser CM (2000). Trauma to the central nervous system may result in formation or enlargement of multiple sclerosis plaques. Arch. Neurol. 57:1074-1077.

QGIS (2015). QGIS: A Free and Open Source Geographic Information System. Online at http://www.qgis.org/en/site/index.html\#. Accessed November 2015.

Ramagopalan SV, Dobson R, Meier UC, Giovannoni G (2010). Multiple Sclerosis: risk factors, prodomes, and potential casual pathways. Lancet Neurol. 9:727-739. doi: 10.1016/S1474-4422(10)70094-6.

Ramagopalan SV, Hande AE, Giovannoni G, Siegel SR, Ebers GC, Chaplin G, (2011). Relationship of UV exposure to prevalence of multiple sclerosis in England. Neurology 76:14101414. doi: 10.1212/WNL.0b013e318216715e.

Rees DM, Bradley EJ, Green BMR (2010). Radon in homes in England and Wales: 2010 Data Review. HPA-CRCE-015: ISBN 978-0-85951-688-4.

Robertson N, Compston A (1995). Surveying multiple sclerosis in the United Kingdom. J. Neurol. Neurosurg. Psychiatry, 58:2-6 (1995).

Segi M (1960). Cancer mortality for selected sites in 24 countries (1950-57). Department of Public Health, Tohoku University of Medicine, Sendai, Japan.

Simpson J, Blizzard L, Otahal P, Van der Mei I, Taylor B (2011). Latitude is significantly associated with the prevalence of Multiple Sclerosis : a meta-analysis. J Neurol. Neurosurg. Psychiatry. 82:1132-1141. doi: 10.1136/jnnp.2011.240432.

Swingler RJ, Compston DAS (1986). The distribution of multiple sclerosis in the United Kingdom. J. Neurol. Neurosurg. Psychiatry, 49:1115-1124.

Townsend P, Phillimore P, Beattie A (1988). Health and Deprivation: inequality and the north. Routledge: London.

Walley T, Mantgani A (1997). The UK General Practice Research Database. The Lancet 350:9084, 1097-1099.

Wingerchuk D (2012). Smoking: effects on multiple sclerosis susceptibility and disease progression. Ther. Adv. Neurol. Disord. 5:13-22. doi: 10.1177/1756285611425694.

Wrixon AD, Green BMR, Lomas PR, Miles JCH, Cliff KD, Francis EA, Driscoll CMH, James AC, O'Riordan MC (1998). Natural radiation exposure in UK dwellings. Didcot: National Radiological Protection Board. 


\section{Tables}

Table 1: Definition of radon Bands 1 - 9, with corresponding numbers of postcode sectors and included homes, with arithmetic (AM) and geometric (GM) mean indoor radon levels, calculated from Green et al. (2002).

\begin{tabular}{|c|c|c|c|c|c|c|c|c|c|}
\hline \multirow[t]{2}{*}{ Band } & \multirow[t]{2}{*}{$\begin{array}{l}\text { Postcode } \\
\text { Sectors }\end{array}$} & \multirow{2}{*}{$\begin{array}{l}\text { Homes } \\
\text { Total }\end{array}$} & \multirow[b]{2}{*}{ Tested } & \multirow{2}{*}{$\begin{array}{l}\text { THIN } \\
\text { Population } \\
\text { 2005-2012 } \\
\text { [person- } \\
\text { years] }\end{array}$} & \multicolumn{2}{|c|}{$\begin{array}{l}\text { Weighted Mean } \\
\text { Radon }\left[\mathrm{Bq} \cdot \mathrm{m}^{-3}\right]\end{array}$} & \multicolumn{3}{|c|}{$\begin{array}{l}\text { Homes projected to exceed } \\
\text { Action Level }\end{array}$} \\
\hline & & & & & $\overline{\mathbf{A M}}$ & GM & Total & $\begin{array}{l}\text { Definition } \\
\%>\text { A.L. }\end{array}$ & $\begin{array}{l}\text { Actual } \\
\%>A L\end{array}$ \\
\hline 1 & 202 & 638390 & 55282 & 505522 & 36 & 27 & 224 & $<=1.0$ & 0.41 \\
\hline 2 & 93 & 263070 & 33281 & 157275 & 47 & 32 & 515 & $1.1-2.0$ & 1.55 \\
\hline 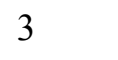 & 133 & 355960 & 67067 & 267162 & 58 & 39 & 2282 & $2.1-5.0$ & 3.40 \\
\hline 4 & 115 & 278270 & 70689 & 192725 & 80 & 52 & 5286 & $5.1-10.0$ & 7.48 \\
\hline 3 & 74 & 179990 & 52337 & 119988 & 106 & 66 & 6567 & $10.1-15.0$ & 12.55 \\
\hline 6 & 39 & 97890 & 31672 & 83356 & 127 & 80 & 5428 & $15.1-20.0$ & 17.14 \\
\hline 7 & 46 & 103770 & 32468 & 46983 & 160 & 99 & 7790 & $20.1-30.0$ & 23.99 \\
\hline 8 & 27 & 53990 & 18980 & 43639 & 218 & 127 & 6554 & $30.1-40.0$ & 34.53 \\
\hline 9 & 14 & 26530 & 9080 & 14 & 312 & 201 & 4790 & $>40.0$ & 52.75 \\
\hline Band & $1-9 \quad 743$ & 1997860 & 370856 & 1416650 & 73 & 63 & 39436 & & 10.63 \\
\hline
\end{tabular}

6 Table 2: Read Codes used in data extraction

\section{Read Code Description}

666A.00 Multiple sclerosis review

666B.00 Multiple sclerosis multidisciplinary review

8CS1.00 Multiple sclerosis care plan agreed

9kG..00 Special Services for patient with multiple sclerosis - enhanced service administration

F20..00 Multiple sclerosis

F20..11 Disseminated sclerosis

F200.00 Multiple sclerosis of the brain stem

F201.00 Multiple sclerosis of the spinal cord

F202.00 Generalised multiple sclerosis

F203.00 Exacerbation of multiple sclerosis

F20z.00 Multiple sclerosis NOS

ZRVE.00 Kurtzke multiple sclerosis rating scale

ZRVE.11 Kurtzke multiple sclerosis scale 
Table 3: Raw extracted data and calculated incidence rate per $10^{5}$ person-years for England and Wales combined, in standard age-bands

(a): Full population (Bands $0-9$ )

\begin{tabular}{lrrrrrrrrr}
\hline \hline \multicolumn{3}{c}{ MS Cases } & \multicolumn{3}{c}{ Person-Years } & \multicolumn{4}{c}{ MS Incidence [10-5 } \\
\hline Age & Female & Male & \multicolumn{1}{l}{ Both } & \multicolumn{1}{l}{ Female } & \multicolumn{1}{l}{ Male } & \multicolumn{1}{l}{ Both } & Female & Male & Both \\
\hline $0-14$ & 3 & 1 & 4 & $1,109,208$ & $1,173,131$ & $2,282,339$ & 0.27 & 0.09 & 0.18 \\
$15-19$ & 15 & 7 & 22 & 591,476 & 675,608 & $1,267,084$ & 2.54 & 1.04 & 1.74 \\
$20-24$ & 27 & 23 & 50 & 438,921 & 564,489 & 1003,410 & 6.15 & 4.07 & 4.98 \\
$25-29$ & 58 & 23 & 81 & 405,197 & 498,611 & 903,808 & 14.31 & 4.61 & 8.96 \\
$30-34$ & 91 & 36 & 127 & 486,577 & 522,709 & $1,009,286$ & 18.70 & 6.89 & 12.58 \\
$35-39$ & 150 & 53 & 203 & 667,870 & 673,230 & $1,341,100$ & 22.46 & 7.87 & 15.14 \\
$40-44$ & 169 & 77 & 246 & 832,750 & 830,303 & $1,663,053$ & 20.29 & 9.27 & 14.79 \\
$45-49$ & 178 & 63 & 241 & 851,240 & 858,599 & $1,709,839$ & 20.91 & 7.34 & 14.09 \\
$50-54$ & 135 & 52 & 187 & 771,590 & 788,267 & $1,559,857$ & 17.50 & 6.60 & 11.99 \\
$55-59$ & 102 & 36 & 138 & 750,967 & 760,526 & $1,511,493$ & 13.58 & 4.73 & 9.13 \\
$60-64$ & 78 & 38 & 116 & 749,137 & 747,803 & $1,496,940$ & 10.41 & 5.08 & 7.75 \\
$65-69$ & 36 & 17 & 53 & 627,071 & 604,729 & $1,231,800$ & 5.74 & 2.81 & 4.30 \\
$70-74$ & 13 & 6 & 19 & 538,073 & 491,167 & $1,029,240$ & 2.42 & 1.22 & 1.85 \\
$75-79$ & 8 & 6 & 14 & 473,091 & 392,496 & 865,587 & 1.69 & 1.53 & 1.62 \\
$80-84$ & 4 & 3 & 7 & 381,095 & 270,477 & 651,572 & 1.05 & 1.11 & 1.07 \\
$85+$ & 3 & 1 & 4 & 409,607 & 204,483 & 614,090 & 0.73 & 0.49 & 0.65 \\
\hline Total & 1070 & 442 & 1512 & $10,083,870$ & $10,056,628$ & $20,140,498$ & 10.61 & 4.40 & 7.51 \\
\hline \hline
\end{tabular}

(b): Validated residents of Bands $1-8$

\begin{tabular}{lcrrrrrrrr}
\hline \hline & \multicolumn{1}{c}{ MS Cases } & \multicolumn{3}{c}{ Person-Years } & \multicolumn{4}{c}{ MS Incidence $\left[10^{-5}\right]$} \\
\hline Age & Female & Male & Both & \multicolumn{1}{l}{ Female } & \multicolumn{1}{l}{ Male } & \multicolumn{1}{c}{ Both } & Female & Male & Both \\
\hline $0-14$ & 0 & 0 & 0 & 79,613 & 84,366 & 163,979 & 0.00 & 0.00 & 0.00 \\
$15-19$ & 1 & 0 & 1 & 42,529 & 49,719 & 92,248 & 2.35 & 0.00 & 1.08 \\
$20-24$ & 3 & 1 & 4 & 30,017 & 40,699 & 70,716 & 9.99 & 2.46 & 5.66 \\
$25-29$ & 4 & 4 & 8 & 25,502 & 33,565 & 59,067 & 15.69 & 11.92 & 13.54 \\
$30-34$ & 4 & 0 & 4 & 30,709 & 34,374 & 65,083 & 13.03 & 0.00 & 6.15 \\
$35-39$ & 13 & 5 & 18 & 42,379 & 43,943 & 86,322 & 30.68 & 11.38 & 20.85 \\
$40-44$ & 15 & 6 & 21 & 55,939 & 57,832 & 113,771 & 26.81 & 10.37 & 18.46 \\
$45-49$ & 13 & 5 & 18 & 59,637 & 62,271 & 121,908 & 21.80 & 8.03 & 14.77 \\
$50-54$ & 10 & 2 & 12 & 54,070 & 56,834 & 110,904 & 18.49 & 3.52 & 10.82 \\
$55-59$ & 8 & 6 & 14 & 51,743 & 53,290 & 105,033 & 15.46 & 11.26 & 13.33 \\
$60-64$ & 5 & 3 & 8 & 54,313 & 54,836 & 109,149 & 9.21 & 5.47 & 7.33 \\
$65-69$ & 4 & 1 & 5 & 47,369 & 46,941 & 94,310 & 8.44 & 2.13 & 5.30 \\
$70-74$ & 0 & 1 & 1 & 38,348 & 35,943 & 74,291 & 0.00 & 2.78 & 1.35 \\
$75-79$ & 0 & 0 & 0 & 32,657 & 28,012 & 60,669 & 0.00 & 0.00 & 0.00 \\
$80-84$ & 0 & 1 & 1 & 26,164 & 19,241 & 45,405 & 0.00 & 5.20 & 2.20 \\
$85+$ & 0 & 0 & 0 & 28,955 & 14,840 & 43,795 & 0.00 & 0.00 & 0.00 \\
\hline Total & 80 & 35 & 115 & 699,944 & 716,706 & $1,416,650$ & 11.30 & 4.67 & 7.89 \\
\hline \hline
\end{tabular}


1 Table 4: MS incidence (this study and recent UK Studies) for the catchment population.

\begin{tabular}{|c|c|c|c|c|c|c|}
\hline \multirow{2}{*}{ Study } & \multirow{2}{*}{ Geographical Scope } & \multirow{2}{*}{$\begin{array}{l}\text { Time } \\
\text { Frame }\end{array}$} & \multirow{2}{*}{$\begin{array}{l}\text { MS } \\
\text { Cases }\end{array}$} & \multicolumn{3}{|c|}{ MS Incidence $\left[10^{-5}\right]$} \\
\hline & & & & Female & Male & Both \\
\hline \multirow{3}{*}{ This study } & England \& Wales [Raw] & \multirow{3}{*}{$\begin{array}{l}2005- \\
2012\end{array}$} & \multirow{3}{*}{1512} & 10.61 & 4.40 & 7.51 \\
\hline & England \& Wales [UK 2010] & & & 11.43 & 4.88 & 8.12 \\
\hline & England \& Wales [World 1960] & & & 11.80 & 4.77 & 8.12 \\
\hline $\begin{array}{l}\text { Mackenzie et al. } \\
(2014)\end{array}$ & UK & $\begin{array}{l}1990- \\
2010\end{array}$ & 1320 & 11.52 & 4.84 & 9.64 \\
\hline \multirow{2}{*}{ Alonso et al. (2007) } & UK [Raw] & $1993-$ & \multirow{2}{*}{642} & 7.42 & 3.44 & 5.47 \\
\hline & UK [World 1960] & 2000 & & 7.16 & 3.07 & 5.10 \\
\hline
\end{tabular}

3 Table 5: Radon bands - population and coverage. Assumes household size 2.47

\begin{tabular}{|c|c|c|c|c|c|}
\hline Radon Band & $\begin{array}{l}\text { Mean } \\
\text { Band } \\
\text { Radon } \\
\end{array}$ & $\begin{array}{l}\text { MS Cases } \\
(2005- \\
\text { 2012) } \\
\end{array}$ & $\begin{array}{l}\text { THIN Population } \\
\text { (2005-2012) } \\
\text { [person-years] }\end{array}$ & $\begin{array}{l}\text { 2002 Radon } \\
\text { Atlas } \\
\text { Population } \\
\end{array}$ & Coverage \\
\hline 1 & 36 & 44 & 505,522 & $1,589,173$ & $3.98 \%$ \\
\hline 2 & 47 & 10 & 157,275 & 658,675 & $2.98 \%$ \\
\hline 3 & 58 & 19 & 267,162 & 880,802 & $3.79 \%$ \\
\hline 4 & 80 & 13 & 192,725 & 684,610 & $3.52 \%$ \\
\hline 5 & 106 & 8 & 119,988 & 450,503 & $3.33 \%$ \\
\hline 6 & 127 & 11 & 83,356 & 241,788 & $4.31 \%$ \\
\hline 7 & 160 & 7 & 46,983 & 249,396 & $2.35 \%$ \\
\hline 8 & 218 & 3 & 43,639 & 149,410 & $3.65 \%$ \\
\hline 9 & 312 & 0 & 14 & 56,390 & $0.00 \%$ \\
\hline Total $(1-9)$ & 73 & 115 & $1,416,650$ & $4,960,747$ & \\
\hline 0 & & 1397 & $18,152,817$ & \multicolumn{2}{|c|}{ Not included in radon analysis } \\
\hline All & & 1512 & $19,569,467$ & $49,662,100$ & $5.07 \%$ \\
\hline
\end{tabular}


Table 6: MS incidence by radon band for England and Wales:
(a) Raw incidence
(b) Incidence standardised to England and Wales 2010 population (ONS, 2011)
(c) Incidence standardised to World Standard Population (Bray, 2002)

\begin{tabular}{|c|c|c|c|c|c|c|c|}
\hline \multirow{2}{*}{$\begin{array}{l}\text { Radon } \\
\text { Band }\end{array}$} & \multirow{2}{*}{$\begin{array}{l}\text { Mean Radon } \\
\text { Level } \\
{\left[\mathrm{Bq} \cdot \mathbf{m}^{-3}\right]}\end{array}$} & \multicolumn{2}{|c|}{ Female } & \multicolumn{2}{|c|}{ Male } & \multicolumn{2}{|c|}{ Both } \\
\hline & & Cases & $\begin{array}{c}\text { Incidence } \\
10^{-5} \\
\end{array}$ & Cases & $\begin{array}{c}\text { Incidence } \\
10^{-5} \\
\end{array}$ & Cases & $\begin{array}{c}\text { Incidence } \\
10^{-5} \\
\end{array}$ \\
\hline (a) & Raw Incidence & & & & & & \\
\hline 1 & 36 & 31 & 12.33 & 13 & 5.12 & 44 & 8.70 \\
\hline 2 & 47 & 6 & 7.72 & 4 & 5.03 & 10 & 6.36 \\
\hline 3 & 58 & 10 & 7.64 & 9 & 6.61 & 19 & 7.11 \\
\hline 4 & 80 & 9 & 9.39 & 4 & 4.13 & 13 & 6.75 \\
\hline 5 & 106 & 7 & 11.95 & 1 & 1.63 & 8 & 6.67 \\
\hline 6 & 127 & 8 & 19.53 & 3 & 7.08 & 11 & 13.20 \\
\hline 7 & 160 & 7 & 30.34 & 0 & 0.00 & 7 & 14.90 \\
\hline 8 & 218 & 2 & 9.36 & 1 & 4.49 & 3 & 6.87 \\
\hline 9 & 312 & 0 & 0.00 & 0 & 0.00 & 0 & 0.00 \\
\hline $1-9$ & 73 & 80 & & 35 & & 115 & \\
\hline $0-9$ & 124 & 1070 & 10.60 & 442 & 4.40 & 1512 & 7.50 \\
\hline
\end{tabular}

(b) Standardised to England and Wales 2010 Population (Bray, 2002)

\begin{tabular}{lrrrr}
\hline 1 & 36 & 12.39 & 4.47 & 8.85 \\
2 & 47 & 8.31 & 6.76 & 6.36 \\
3 & 58.36 & 7.63 & 6.32 \\
4 & 8.58 & 3.93 & 6.44 \\
5 & 10.74 & 1.40 & 5.87 \\
6 & 106 & 11.33 & 12.54 \\
7 & 127 & 0.99 & 0.00 & 14.40 \\
8 & 160 & 30.25 & 16.05 & 9.17 \\
9 & 218 & 0.00 & 0.00 \\
\hline $0-9$ & 312 & 0.00 & 4.16 & 7.17 \\
\hline \hline c) & Standardised to World Standard Population (Segi, 1960) & & \\
\hline 1 & 36 & 11.11 & 4.94 & 8.00 \\
2 & 47 & 7.59 & 3.75 & 5.47 \\
3 & 58 & 4.95 & 4.92 & 4.98 \\
4 & 80 & 8.54 & 2.56 & 5.39 \\
5 & 106 & 0.67 & 4.82 & 4.65 \\
6 & 127 & 18.09 & 0.00 & 10.70 \\
7 & 160 & 27.09 & 5.31 & 12.52 \\
8 & 218 & 15.86 & 0.00 & 9.12 \\
9 & 312 & 0.00 & 3.55 & 0.00 \\
\hline $0-9$ & 73 & 8.97 & & 6.06 \\
\hline \hline
\end{tabular}

